\title{
Structural behaviour and gene delivery in complexes formed between DNA and arginine-containing peptide amphiphiles
}

Article

Accepted Version

Silva, E. R., Cooney, G., Hamley, I. W., Alves, W. A., Lee, S., O'Connor, B. F., Reza, M., Ruokolainen, J. and Walls, D. (2016) Structural behaviour and gene delivery in complexes formed between DNA and arginine-containing peptide amphiphiles. Soft Matter, 12 (45). pp. 9158-9169. ISSN 1744683X doi: https://doi.org/10.1039/C6SM01618A Available at https://centaur.reading.ac.uk/68127/

It is advisable to refer to the publisher's version if you intend to cite from the work. See Guidance on citing.

To link to this article DOI: http://dx.doi.org/10.1039/C6SM01618A

Publisher: Royal Society of Chemistry

All outputs in CentAUR are protected by Intellectual Property Rights law, including copyright law. Copyright and IPR is retained by the creators or other copyright holders. Terms and conditions for use of this material are defined in the End User Agreement. 


\section{CentAUR}

Central Archive at the University of Reading

Reading's research outputs online 


\title{
Structural Behaviour and Gene Delivery in Complexes Formed
}

\section{Between DNA and Arginine-Containing Peptide Amphiphiles}

\author{
Emerson R. da Silva ${ }^{a, b *}$, Gary Cooney ${ }^{c}$, Ian W. Hamley ${ }^{d}$, Wendel A. Alves ${ }^{a}$, Shannon Lee ${ }^{c}$, \\ Brendan F. O'Connor ${ }^{c}$, Mehedi Reza ${ }^{e}$, Janne Ruokolainen $^{e}$ and Dermot Walls ${ }^{c}$ \\ ${ }^{a}$ Centro de Ciências Naturais e Humanas, Universidade Federal do ABC, Santo André-SP, \\ 09210-580, Brazil \\ ${ }^{b}$ Instituto de Física, Universidade Federal de Alagoas, Maceió-AL, 57072-900, Brazil \\ ${ }^{c}$ School of Biotechnology and National Centre for Sensor Research, Dublin City University, \\ Dublin 9, Ireland \\ ${ }^{d}$ Department of Chemistry, University of Reading, Whiteknights, RG6 6AD, United Kingdom \\ ${ }^{e}$ Department of Applied Physics, Aalto University School of Science, P.O. Box 15100, FI-00076, \\ Finland
}

\begin{abstract}
We describe in depth the structure of complexes formed between DNA and two classes of arginine-containing peptide amphiphiles, namely, the lipopeptide $\mathrm{PRW}-\mathrm{C}_{16}(\mathrm{P}=$ proline, $\mathrm{R}=$ arginine, $\mathrm{W}=$ tryptophan, $\mathrm{C}_{16}=\mathrm{C} 16: 0$ alkyl chain $)$ and the bolaamphiphile $\mathrm{RFL}_{4} \mathrm{FR}(\mathrm{R}=$ arginine, $\mathrm{F}=$ phenylalanine, $\mathrm{L}=$ leucine). A combination of $\mathrm{X}$-ray and neutron scattering provided unprecedented insights into the local structure of these complexes. Lipopeptide-based complexes self-assembled into layered structures with large-scale fractal features, hosting DNA in the interstices. Bola-amphiphile scaffolds were characterized by planar structures with DNA strands presumably sandwiched in-between peptide nanotapes. Importantly, complexation did not affect the structural integrity of DNA in either of the two complexes. The bolaamphiphile conjugates displayed high levels of molecular ordering in contrast to the liquid-crystalline features observed in lipopeptide assemblies. Peptide-DNA complexes were assessed for their potential as a means to deliver the reporter vector pEGFP-N1 into SW480 human colon carcinoma cells. Successfully transfected cells expressed Green Fluorescent Protein. The potentiating effect of PRW-C $\mathrm{C}_{16}$ on the cellular uptake of ectopic DNA was found to be much greater than that observed with $\mathrm{RFL}_{4} \mathrm{FR}$. In contrast to bolaamphiphile-based conjugate, the liquid-crystalline nature of the lipopeptide complex is likely to play a key role in DNA release and transfection efficiency since these weakly bound structures require lower energy expenditure during disassembly and load release.
\end{abstract}

Key-words: self-assembly, transfection, gene therapy, synthetic vectors, SW480, SAXS, SANS 


\section{Introduction}

Synthetic complexes for the transport and release of nucleic acids (NAs) are alternative delivery systems to engineered viral vectors with applications in the area of nucleic acid therapeutics including gene therapy. ${ }^{1,2}$ The concept consists of creating a synthetic envelope to encapsulate polynucleotides, forming scaffolds that can be carefully designed to protect the cargo, promoting uptake across the membranes of targeted eukaryotic cells and facilitating endosomal escape following cellular uptake. ${ }^{3}$ Electrostatically, nucleotide sequences are highlyanionic polyelectrolytes that carry one charge per phosphate group under physiological conditions. ${ }^{4}$ This characteristic has led to a considerable focus on various cationic species as obvious candidates for complex formation with DNA. ${ }^{5}$ Despite Coulomb attraction being evident in these systems however, there is general consensus that the entropy effects that appear upon counter-ion release from oppositely charged macromolecules are the underlying mechanism leading to the formation of thermodynamically stable complexes. ${ }^{6,7}$ Lipids and polymers have been a preferred choice for designing non-viral carriers, which are often referred to as lipoplexes and polyplexes, respectively. ${ }^{1}$ Conjugates formed between NAs and amphiphilic moieties can self-assemble into a wide variety of liquid crystalline polymorphs, ${ }^{5,8}$ including multilamellar (“onion-like") arrays, ${ }^{7}$ disc-shaped bicelles, ${ }^{9}$ hexagonal structures, ${ }^{10}$ and cubic phases. ${ }^{11}$ Since cell transfection efficiency has been found to be dependent on a number of factors, including charge density and structural features, ${ }^{12}$ an accurate understanding of the spatial organization within such transfection complexes is of key importance in order to optimize intracellular cargo delivery. ${ }^{5}$

Synthetic peptides are promising candidates as molecular carriers for biomedical applications thanks to their wide chemical diversity, ease of synthesis and intrinsic biocompatibility. ${ }^{13,}{ }^{14}$ Recently, conjugates involving peptide self-assemblies have been formulated for molecular transport and their toxicity towards eukaryotic cells has been investigated. ${ }^{15-17}$ Previous studies conducted by our groups have also demonstrated the ability of arginine-rich sequences to self-assemble into nanoscopic polymorphs where cationic groups 
appear spread across the interfaces of the nanostructures, thus being candidates to form complexes with anionic species. ${ }^{16,18,19}$ Here, we expand on these prior studies and scrutinize in detail the structure of conjugates obtained between DNA (both small linear fragments and plasmid vector) and short arginine-containing peptide amphiphiles (PAs). Arginine-rich sequences have been widely demonstrated to be highly efficient when it comes to promoting cell uptake and are extensively found in cell penetrating peptides (CPPs) ${ }^{20,21}$ Several studies in which arginine-containing carriers have been compared to others containing cationic amino acids, including lysine which is also frequently used in CPPs, ${ }^{20}$ have systematically shown that arginine is more efficient at promoting membrane penetration. ${ }^{21,22,23}$ This has been attributed to the diffuse charge distribution and stronger H-bond donating capabilities observed in guanidium groups on arginine side-chains. In the current work, we also investigate the transfection potential of these PA/DNA complexes by monitoring the expression of plasmid-encoded enhanced green fluorescent protein (EGFP) in a human colon carcinoma cell line (SW480).

In Figure 1, we show the chemical structures of arginine-based PAs used to produce conjugates with double-stranded DNA. Two types of PAs were used in our complexes: a surfactant-like peptide with a head group consisting of a PRW $(\mathrm{P}=$ proline, $\mathrm{R}=$ arginine, $\mathrm{W}=$ tryptophan) tripeptide, and a bolaamphiphile compound with the sequence $\mathrm{RFL}_{4} \mathrm{FR}(\mathrm{R}=$ arginine, $\mathrm{F}=$ phenylalanine, $\mathrm{L}=$ leucine). ${ }^{16}$ Inclusion of the lipopeptide head group was based on the recognized effectiveness of arginine groups for enhancing cell membrane permeation ${ }^{20,24}$ and on the observation of the high frequency with which proline-rich sequences are seen in amphipathic cell-penetrating peptides ${ }^{25}$ (CPPs). In addition, tryptophan has been found to be a crucial residue for the uptake of CPPs and, thanks to its hydrophobic nature, it has also been assessed for interaction with the core of lipid plasma membranes. ${ }^{26}$ In the arginine-capped bolaamphiphile sequence, these moieties are thought to help membrane adhesion whereas the highly-hydrophobic $\mathrm{FL}_{4} \mathrm{~F}$ central spacer assists the formation of stable nanosheets in water at very low concentrations. ${ }^{16,27}$ We investigated the structure of PA/NA-complexes using a range of biophysical techniques including small-angle X-ray and neutron scattering (SAXS and SANS), fibre X-ray diffraction (XRD) and high-resolution cryogenic electron microscopy 
(cryo-TEM) imaging. To formulate the complexes, we first used short NA fragments $[\sim 150$ base pairs (bp)] obtained through sonication of calf thymus DNA. Once PA/DNA complexation was verified, we extended our investigations to include PA conjugation with the eukaryotic expression vector pEGFP-N1. This 4.7 kilobase pair $(\mathrm{kbp})$ plasmid is usually in a super coiled state in solution and encodes a red-shifted variant of Green Fluorescent Protein (EGFP) which has been optimized for detection and expression in mammalian cells thus making it a suitable marker for cell transfection efficiency and DNA functionality following uptake by cells. Due to its larger size, the delivery of plasmid DNA can be very challenging. ${ }^{28}$ Conjugation with peptides however potentially induces DNA condensation, thereby reducing size and thus facilitating penetration across plasma and nuclear membrane barriers. Unlike other nucleotides, such as short interfering RNA (siRNA) which requires only cytoplasmic release, plasmid DNA requires intra-nuclear delivery as a pre-requisite for gene expression. We demonstrate here the interaction of these lipopeptide and bolaamphiphilic peptides with plasmid DNA and show their capacity to enhance the cellular uptake of their cargo whilst maintaining its functionality as evidenced by the expression of EGFP in target cells.

\section{Materials and Methods}

Peptide Amphiphiles: Both peptides were custom-synthesized by CS Bio (Merlo Park, CA, USA), with TFA as a counter ion. The lipopeptide PRW- $\mathrm{C}_{16}$ had its purity determined to be 95.4\% and a molar mass of $\mathrm{M}_{\mathrm{w}}=681.6 \mathrm{~g}$ (expected $681.98 \mathrm{~g}$ ), as attested by HPLC and electrospray-mass spectroscopy. The bolaamphiphile $\mathrm{RFL}_{4} \mathrm{FR}$ had a purity of $97.5 \%$ and a molar mass of $\mathrm{M}_{\mathrm{w}}=1076.86 \mathrm{~g}$ (expected: $1076.36 \mathrm{~g}$ ). In both cases the dry powder was kept refrigerated at $-20{ }^{\circ} \mathrm{C}$ and samples were prepared by dissolving weighed amounts into ultrapure water. Prior to mixing with DNA, peptides were dissolved at $10 \mathrm{mg} / \mathrm{mL}$ in Trizma buffer $(\mathrm{pH}$ adjusted at 7.4) or Phosphate Buffered Saline (PBS) buffer ( $\mathrm{pH}$ at 7.4). In the case of $\mathrm{RFL}_{4} \mathrm{FR}$, samples were ultrasonicated for about $20 \mathrm{~min}$ at $\sim 55^{\circ} \mathrm{C}$ in order to reach complete dissolution. 
in the form of dried fibres. These were re-hydrated with ultrapure water and transferred into glass vials at a concentration of $10 \mathrm{mg} / \mathrm{mL}$. They were then homogenised by vigorous shaking for $2 \mathrm{~h}$ and sonicated for about $30 \mathrm{~h}$ in an ultrasound bath until fragments of average size $150 \mathrm{bp}$ were obtained as determined by electrophoresis, as previously reported. ${ }^{29,}{ }^{30}$ The fragments used in further experimentation had sizes generally roughly corresponding to the DNA persistence length (i.e., $50 \mathrm{~nm}$ ). The vector pEGFP-N1 (Clontech Laboratories, Mountain View, CA, USA) was used for PA/plasmid interaction gel retardation assays [also known as Bandshift or Electrophoretic Mobility Shift Assays (EMSA)] and for transfection studies. This 4.7 kilobase pair plasmid expresses an enhanced green fluorescent protein (EGFP) and was purified from $E$. coli DH5 $\alpha$ using a QIAGEN plasmid purification maxi kit (Valencia, CA, USA). The purity and concentrations of plasmid preparations were ascertained by agarose gel electrophoresis (1\% agarose) and UV absorption using a NanoDrop instrument (Thermo Scientific, Wilmington, DE, USA), respectively.

PA/DNA complexes: Peptides and DNA were dissolved in buffer (100 mM Trizma or PBS, $\mathrm{pH}$ 7.4) at typical final concentrations of $\sim 5 \mathrm{mg} / \mathrm{mL}$ for peptides and $\sim 3 \mathrm{mg} / \mathrm{mL}$ for DNA. Concentrations were chosen so that arginine-to-phosphate molar ratios were equal to one. Thus, calculations were made considering two phosphate groups per nucleotide base pair $\left(\mathrm{M}_{\mathrm{w}}=660\right.$ g), one arginine side-chain per molecule of lipopeptide PRW- $\mathrm{C}_{16}$ and two arginine residues per bolaamphiphilic sequence $\mathrm{RFL}_{4} \mathrm{FR}$. Under these conditions, formulations made with plasmid formed a white precipitate upon mixing, whereas samples prepared with DNA fragments formed a turbid solution. In neutron scattering assays, the procedure was similar to that described above; however, samples were diluted using $\mathrm{H}_{2} \mathrm{O} / \mathrm{D}_{2} \mathrm{O}$ mixtures (see details below).

Cryo-TEM assays: Cryogenic transmission electron microscopy (cryo-TEM) imaging was performed as detailed elsewhere. ${ }^{16}$ Briefly, the instrument was a JEOL JEM-3200FSC operating at $300 \mathrm{kV}$. The microscope was used in bright-field mode with a slit width of $20 \mathrm{eV}$ and images were recorded with a Gatan Ultrascan $4000 \mathrm{CCD}$ camera. Droplets containing about $3 \mu \mathrm{L}$ of PA/DNA suspensions were cast onto copper grids, blotted once for $1 \mathrm{~s}$ and then vitrified (in a 
FEI Vitrobot device) in a $1: 1$ mixture of liquid ethane and propane at $-180{ }^{\circ} \mathrm{C}$. Grids with vitrified samples were maintained in liquid nitrogen before being transferred into the microscope.

X-ray diffraction (XRD): XRD patterns were obtained from dried stalks. Pellets of PA/DNA complexes were suspended between the ends of wax-coated capillaries. This assembly was carefully placed within Petri dishes sealed with parafilm and left to dry for a period of days within the fridge at $4^{\circ} \mathrm{C}$. To facilitate the drying process, silica gel beads were deposited within the Petri dishes. Typically, the formation of dried stalks was observed after 3-4 days of incubation. Stalks were vertically positioned onto a RAXIS IV++X-ray diffractometer (Rigaku) using a rotating anode generator as X-ray source. Data were registered using a Saturn 992 CCD camera at a sample-to-detector distance of $40 \mathrm{~mm}$. Data reduction was performed using Fit2D software (ESRF) and unit cell optimization and simulations were carried out with the program CLEARER. $^{31}$

Synchrotron Small-Angle X-ray Scattering (SAXS) : Synchrotron SAXS from samples prepared with the lipopeptide PRW- $\mathrm{C}_{16}$ was performed on the beamline SWING at SOLEIL (Saint Aubin, France), whereas preparations made with the bolaamphiphile $\mathrm{RFL}_{4} \mathrm{FR}$ were examined on beamline I911-4 at MaxLab II (Lund, Sweden). On SWING-SOLEIL, the wavelength was set at $\lambda=1.03 \AA$ and sample-to-detector distance was $1,526.4 \mathrm{~mm}$. SAXS patterns were recorded using a 2D Aviex 170170 detector. Measurements in solutions containing DNA fragments were performed using the bioSAXS setup with the automatic sample changer available on the beamline. About $50 \mu \mathrm{L}$ of each solution containing PA/DNA complexes were flowed through a $1 \mathrm{~mm}$ quartz-capillary. Automated washing steps were performed between every measurement and background assessments were made prior to and after sample registering. To avoid radiation damage, 50 frames (500 $\mathrm{ms}$ per frame) were grabbed during sample flow. The frames were compared and, if no damage was detected, they were averaged and the background was subtracted. For samples prepared with plasmid, plasmid/peptide pellets were transferred into individual $1 \mathrm{~mm}$ quartz capillaries and centrifuged 
to the bottom. On beamline I911-4 at MaxLab, the procedure was quite similar. The X-ray wavelength was $\lambda=0.91 \AA$ and the sample-to-detector distance was $915 \mathrm{~mm}$. Data was recorded by a Pilatus $1 \mathrm{M}$ detector and 4 frames, $30 \mathrm{~s}$ each, were recorded, compared and, if no radiation damage was observed, averaged. Radial averaging was performed with Fit2D and frame averaging and background subtraction was carried out using the SAXS Utilities program.

Small-Angle Neutron Scattering (SANS): SANS experiments were carried out either on the SANS-1 instrument at the Heinz-Meier Leibnitz Zentrum (MLZ) reactor (Garching, Germany), or on the time-of-flight LOQ beamline, at the ISIS spallation source (Didicot, UK). On SANS-1 at -MLZ, where complexes formed between short DNA fragments and the peptide bolaamphiphile $\mathrm{RFL}_{4} \mathrm{FR}$ were investigated, the neutron beam had $\lambda=5.5 \AA(\Delta \lambda / \lambda=6 \%)$ and cross section $\varnothing=8 \mathrm{~mm}$. Three geometries were used to cover a wide $q$-range: sample-todetector distance SDD $=19.99 \mathrm{~m}$ with collimation $\mathrm{COL}=20 \mathrm{~m}, \mathrm{SDD}=7.99 \mathrm{~m}$ with $\mathrm{COL}=8$ $\mathrm{m}$ and $\mathrm{SDD}=1.2 \mathrm{~m}$ with $\mathrm{COL}=4 \mathrm{~m}$, leading to scattering vectors in the interval $0.05 \mathrm{~nm}^{-1} \leq q$ $\leq 6 \mathrm{~nm}^{-1}$. Detection was performed by an array of $128{ }^{3} \mathrm{He}$ position-sensitive tubes, with an area of $1000 \times 1020 \mathrm{~mm}^{2}$ and a resolution of $8 \mathrm{~mm}$. Radial averaging and data reduction were performed using the package BerSANS. A cadmium shield was placed in front of the beam to assess electronic noise and measurements of empty beam and water transmission were performed in order to correct and normalize the data. On LOQ at ISIS, where conjugates between DNA fragments and the lipopeptide PRW-C ${ }_{16}$ were probed, sample-to-detector distance was kept at SDD $=4 \mathrm{~m}$ and a "white" beam with $\varnothing=12 \mathrm{~mm}$ and wavelengths in the range $2.2 \AA \leq \lambda \leq 10 \AA$ allowed access to the $q$-range interval of $0.2 \mathrm{~nm}^{-1} \leq q \leq 2.5 \mathrm{~nm}^{-1}$. Detection was carried out by a ${ }^{3} \mathrm{He}-\mathrm{CF}_{4}$ area detector with an active surface of $640 \times 640 \mathrm{~mm}^{2}$. Data reduction was performed with the Mantid package. All samples were loaded into Hellma banjo cells with a path length $l=1 \mathrm{~mm}$. Since nucleotides and peptides have very different scattering length densities (SLD) for neutron scattering, samples for SANS were formulated using the solvent matching approach. ${ }^{32}$ This technique consists in preparing solutions with different proportions of $\mathrm{D}_{2} \mathrm{O}$ in the solvent to separately match SLDs of different phases in the 
complexes. At least four samples of PA/DNA fragments complex (peptide at $5 \mathrm{mg} / \mathrm{mL}$ ) were dissolved in solutions with $\mathrm{D}_{2} \mathrm{O} /\left[\mathrm{D}_{2} \mathrm{O}+\mathrm{H}_{2} \mathrm{O}\right]$ molar ratios of $0 \%$ (fully hydrogenated solvent), $39 \%, 66 \%$ and $100 \%$ (fully deuterated). Ratios of $39 \%$ and $66 \%$ were chosen to match the SLD of peptides and DNA, respectively. ${ }^{33}$ Fully hydrogenated or fully deuterated mixtures were used for providing highly positive and highly negative contrasts, respectively. ${ }^{33}$

Gel retardation assays: Varying quantities of each peptide were added to $100 \mathrm{ng}$ of plasmid in a final volume of $10 \mu \mathrm{L}$. Peptide/plasmid mixtures were incubated for $30 \mathrm{~min}$ at $37{ }^{\circ} \mathrm{C}$ and then electrophoresed in 1\% agarose with Tris-Acetate-EDTA (TAE) buffer. Gels were stained using SyBr-Safe (ThermoFisher Scientific) prior to band visualization using a UV transilluminator. The appearance of plasmid bands with reduced electrophoretic mobility was evidence of PA/DNA complexation.

Cell culture, cytotoxicity assays and in vitro transfections: SW480 cells (DSMZ Braunschweig, Germany) were grown in Dulbecco's Minimal Essential Medium (DMEM) supplemented with heat-inactivated $10 \%$ foetal bovine serum (FBS) and $1 \%$ penicillinstreptomycin at $37{ }^{\circ} \mathrm{C}$ in a humidified $5 \% \mathrm{CO}_{2}$ atmosphere. Cells were split and fed immediately prior to confluence every 2 to 3 days following removal with trypsin/EDTA (all cell culture products were from Gibco/Thermo Fischer Scientific, Waltham, MA, USA). Peptide cytotoxicity was evaluated using the fluorogenic indicator dyes Alamar blue [AlamarBlue ${ }^{\circledR}$ (AB) (Bio-Source, Invitrogen)] and CFDA-AM (5-carboxyfluorescein diacetate acetoxymethyl ester; Molecular Probes, Invitrogen), essentially as described elsewhere. ${ }^{34}$ A linear relationship between cell number/well and absorption was first established and based on this SW480 cells were seeded under test conditions at 25,000 cells/well of a black 96 well plate. In brief, after 48 $\mathrm{h}$ of incubation with peptide, the medium was removed completely and $100 \mu \mathrm{L} /$ well of the Alamar blue/CFDA-AM working solution was added. Fluorescence was measured 30 min later at $530 \mathrm{~nm}$ excitation/590 $\mathrm{nm}$ emission for $\mathrm{AB}$ and $485 \mathrm{~nm} / 535 \mathrm{~nm}$ for CFDA-AM, respectively, using a multi-well scanning spectrophotometer. Average values of triplicates were calculated following background correction and cited as "viability (\%)" following reference to vehicle- 
only treated controls. Cell uptake was also qualitatively assessed through fluorescence microscopy assays. SW480 cells were seeded as above in 96 well plates $24 \mathrm{~h}$ before transfection. On the day of transfection a quantity of each peptide (300 ng of PRW- $\mathrm{C}_{16}$ or 250 ng of $\mathrm{RFL}_{4} \mathrm{FR}$ ) was added to $100 \mathrm{ng}$ of plasmid (pEGFP-N1), made up to a volume of $20 \mu \mathrm{l}$ using molecular grade water and incubated at $37^{\circ} \mathrm{C}$ for $30 \mathrm{~min}$ to allow peptide-DNA complexation. Cell culture medium was then removed and replaced with $100 \mu \mathrm{l}$ of fresh serumfree medium containing peptide-DNA complex $(80 \mu \mathrm{l}$ medium plus $20 \mu$ peptide-DNA complex) followed by incubation at $37^{\circ} \mathrm{C}$ for $1 \mathrm{~h}$. Culture medium containing peptide-DNA complex was then removed and replaced with fresh complete medium. The transfection reagent Lipofectamine 2000 (Invitrogen, Carlsbad, CA, USA) was used as per manufacturer's instructions. Forty-eight hours after transfection, cells were stained with Diamidino-2phenylindole (DAPI) and observed using an Olympus BX51 Fluorescent Microscope. Images were split into separate channels (DAPI and EGFP) and analysed using Image $\mathbf{J}$ software. Three images were scored for each condition (a total of at least 500 cells in each case). Transfection efficiencies were estimated by dividing the number of cells with EGFP fluorescence by the number of DAPI-stained nuclei and expressed as percentages. Each DAPI-stained nucleus was counted as one cell. The data presented was compiled from three independent experiments and are presented as means \pm standard deviations $( \pm \mathrm{SD})$.

\section{Results and Discussion}

\section{Structural analysis of peptide complexation with short DNA fragments}

We first ascertained the structure of complexes formed between PAs and short DNA fragments. The goal of these preliminary studies was to probe the viability of complexation using model conjugates which are likely to be simpler than complexes prepared from highmolecular-weight sequences. ${ }^{29,} 35$ The fragments were $\sim 150$ base pairs long, roughly corresponding to the persistence length of the biopolymer. ${ }^{4}$ In this case, DNA duplexes could be approximated by rigid rods with lengths of $\sim 50 \mathrm{~nm}$ and diameters of $\sim 2 \mathrm{~nm}$. As will be 
discussed below, the local structure of complexes using DNA fragments retains remarkable similarities with the local structures of complexes made from plasmid DNA. Another advantage of using such short fragments as a model is their relatively low cost in contrast to longer plasmid sequences. This is a critical issue, especially for preparing samples for neutron scattering which require much larger DNA quantities than those needed for transfection assays or structural analyses using X-rays or cryo-TEM.

In Figures $2 \mathrm{~A}$ and $\mathrm{B}$, we show high-resolution SAXS either from single-phase formulations - i.e., samples containing only DNA or PAs - or from preparations with peptides and nucleic acids dissolved at a 1:1 arginine-to-phosphate ratio. Scattering profiles from singlephase samples were smooth, without Bragg peaks and can be modelled in terms of analytical form factors ${ }^{36}$. Data collected from solutions containing only DNA fragments (bottom curves in Figure 2A and B) was fitted according to a cylinder-shell form factor ${ }^{33,36}$ with fitting parameters of $L=51.9 \mathrm{~nm}$ for the length, $R=0.98 \mathrm{~nm}$ for the core radius and $\Delta R=0.40 \mathrm{~nm}$ for the shell thickness. These values are in close agreement with dimensions expected for $150 \mathrm{bp}$ DNA rods plus $\mathrm{Na}^{+}$counter ion solvation shells. ${ }^{37}$ The cylinder-shell form factor was also used for fitting data from samples prepared with the lipopeptide $\mathrm{PRW}-\mathrm{C}_{16}$ dissolved in buffered solutions (middle curve in Figure 2A). The fitting parameters were as follows: $L=187.4 \mathrm{~nm}, R=1.61$ $\mathrm{nm}$ and $\Delta R=1.33 \mathrm{~nm}$, consistent with cylindrical micelles with cores built up from C16:0 alkyl chains $^{38}$ and outer shells made up from a tripeptide functional group $(3 \times 0.34=1.02 \mathrm{~nm})$ plus a counter ion layer. ${ }^{39}$ SAXS profiles from solutions containing the bolaamphiphile $\mathrm{RFL}_{4} \mathrm{FR}$ (middle curve in Figure 2B) were consistent with nanosheets as previously described. ${ }^{16}$ SAXS data from these formulations was fitted with a bilayer form factor, ${ }^{40}$ revealing an effective membrane thickness of $t=3.0 \mathrm{~nm}$, in agreement with bolaamphiphile membranes built up from pairing of octameric strands with length $8 \times 0.34=2.7 \mathrm{~nm}^{39}$ plus a counter ion solvation shell.

SAXS curves from samples containing both DNA and peptides are much more intricate than data from single-phase solutions. We found that these curves are not appropriately described by linear combinations of their single components, a finding that has been interpreted 
as evidence for complexes in solution. ${ }^{33}$ In this case, curves were dominated by Bragg peaks at intermediate $q$-range (black arrows in Figure 2) indicating the presence of highly-ordered structures at the nanoscale level and pointing out the appearance of new levels of organization in the assemblies. Analysis of scattering behaviour across the $q$-range examined revealed valuable information on the multi-hierarchical structure of the arrays. The low- $q$ range of SAXS profiles from samples incorporating the lipopeptide PRW- $\mathrm{C}_{16}$ was characterized by a linear descent scaling with $\sim q^{-3.6}$ (upper curve in Figure 2A). This value for the Porod exponent reveals a typical feature of long-range clustering in biological macromolecules ${ }^{41}$ and suggested structures with sharp interfaces and a surface fractal dimension of $D_{s}=6-3.6=2.4 .^{41,42}$ An intense peak at $q_{0}=1.12 \mathrm{~nm}^{-1}$, followed by its second order at $q_{1}=2.25 \mathrm{~nm}^{-1}$, indicated a repeat distance of $d=2 \pi / \mathrm{q}_{0}=5.6 \mathrm{~nm}$ which can be ascribed to the separation between layers in a lamellar structure containing DNA in the interstices. Since the diameter of double-stranded DNA without a counter ion solvation shell was around $2 \mathrm{~nm},{ }^{4}$ lamellae formed upon complexation can be smaller than rod-like micelles formed by the lipopeptide. In this case, PRW-C 16 likely self-assembled into interdigitated bilayers with a thickness estimated at $\sim 3.6$ $\mathrm{nm}$, similar to the organization observed for other $\mathrm{C}_{16}$ lipopeptides. ${ }^{43}$ We propose that the appearance of these interlocked structures is driven by condensation of PRW- $\mathrm{C}_{16}$ monomers mediated by DNA strands and that this induces the formation of lamellar aggregates with increased amphiphile concentration. This condensation step is then followed by inter-aggregate interactions which promote fusion of local lamellar domains and lead to long-range assemblies with fractal features. The full width at half maximum $(F W H M)$ of the first-order peak was measured through Lorentzian fits (not shown) at $F W H M=0.22 \mathrm{~nm}^{-1}$, implying a correlation length of $\xi=2 \pi / F W H M=28.5 \mathrm{~nm}$, which corresponded to about $d / \xi \approx 5$ correlated layers in the assemblies.

The low-angle regions in the SAXS profiles from solutions prepared with the bolaamphiphile $\mathrm{RFL}_{4} \mathrm{FR}$ exhibited a $\sim \mathrm{q}^{-2}$ behaviour, indicating planar structures in the complexes (upper curve in Figure 2B). The intermediate range was dominated by a strong reflection at $q=1.28 \mathrm{~nm}^{-1}$, corresponding to a periodicity of $d=4.9 \mathrm{~nm}$, in close agreement with 
the summation of one DNA duplex diameter plus the thickness of the octapeptide nanosheets $(d$ $=2 \times 0.98+3.0=4.96 \mathrm{~nm})$. The correlation length was estimated at $\xi=9.1 \mathrm{~nm}$, corresponding to only $~ 1.9 \mathrm{PA} / \mathrm{DNA}$ galleries (on average) and indicating a very low number of correlated sheets. This strong first-order reflection was followed by a shallow shoulder at $q \sim 2.10 \mathrm{~nm}^{-1}$, which was ascribed to interaxial spacing of DNA strands within the plane of nanosheets with periodicity $d_{D N A}=3.0 \mathrm{~nm}$. This distance is enough to accommodate one double helix diameter plus a few hydration layers and it is quite similar to separations found elsewhere in multilamellar complexes prepared with cationic ${ }^{7,} 44$ and zwitterionic lipids. ${ }^{29}, 35$ Putting the findings above together, our SAXS data suggest these bolaamphiphile complexes were organized into flat peptide membranes with DNA strands sandwiched in between nanosheets, with a limited number of galleries of alternating peptides and nucleic acids.

To get further insights into the structure of the complexes, we carried out small-angle neutron scattering (SANS) combined with the contrast-matching technique. ${ }^{32,33}$ The advantage of using neutrons instead of X-rays is that, by changing the relative amount of deuterium in the solvent - i.e., the $\left[\mathrm{D}_{2} \mathrm{O}\right] /\left(\left[\mathrm{H}_{2} \mathrm{O}\right]+\left[\mathrm{D}_{2} \mathrm{O}\right]\right)$ molar ratio -, it is possible to separately match the scattering length density of each phase within the complex and discriminate its scattering from the signal of the other phase. ${ }^{32}$ Our samples were prepared in solvents containing at least four $D_{2} \mathrm{O}$ percentages for providing strong negative contrast $\left(100 \% \mathrm{D}_{2} \mathrm{O}\right)$, strong positive contrast $\left(0 \% \mathrm{D}_{2} \mathrm{O}\right)$ and matching contrast points of DNA $\left(66 \% \mathrm{D}_{2} \mathrm{O}\right)$ and peptides $\left(39 \% \mathrm{D}_{2} \mathrm{O}\right)$. SANS curves from these assays are shown in panels in Figures 2C and D. Looking at SANS data from complexes prepared with the lipopeptide PRW- $\mathrm{C}_{16}$ (Figure 2C), one observes that the curves carry different information depending on the solvent composition. At higher $\mathrm{D}_{2} \mathrm{O}$ amounts, when scattering is dominated by the peptide component, ${ }^{45}$ the curves are characterized by a linear descent at low- $q$ and a Bragg peak at higher $q$. The Porod exponent in this case was determined at -4 and the Bragg peak was found at $q=1.13 \mathrm{~nm}^{-1}$, in close agreement with the SAXS data presented above. Due to the lower resolution of SANS, the second order of this reflection is not detected. Therefore, the presence of surface fractal aggregates and local layered structures with repeat distances of $d=5.5 \mathrm{~nm}$ was also confirmed by neutron scattering. Since 
the general features of the curves remained essentially the same at $66 \% \mathrm{D}_{2} \mathrm{O}$, when scattering from DNA is minimized and signals from the peptide phase is highlighted, we can conclude that the layered structures arose from lipopeptide assembly. As the amount of deuterium in the solvent decreases, the shape of the SANS profiles changes dramatically. At $39 \% \mathrm{D}_{2} \mathrm{O}$, the contrast point of peptides was matched and scattering was dominated by the DNA phase. In this case, the characteristic Porod-like behaviour at low- $q$ region vanished indicating that stiff DNA fragments were not capable of forming a clustered array on their own. In contrast, a diffuse band is still noticeable in the vicinities of $q=1.13 \mathrm{~nm}^{-1}$, suggesting that the periodicity of $d=5.5 \mathrm{~nm}$ was also associated with nucleic acid fragment layers which were likely to be in-between interdigitated bilayers of the template peptide scaffold. In $\mathrm{D}_{2} \mathrm{O}$-free mixtures, the clustering feature at small angles was retrieved since the peptide component now contributes to the overall scattering. The Bragg peak at intermediate range in this case was hidden below incoherent scattering from $\mathrm{H}$ nuclei in the solvent. ${ }^{32}$

SANS data from complexes prepared with the bolaamphiphile $\mathrm{RFL}_{4} \mathrm{FR}$ are shown in Figure 2D. Again, solutions containing higher $\mathrm{D}_{2} \mathrm{O}$ amounts exhibited scattering profiles similar to those observed in SAXS, demonstrating that the overall structure of the complex is mainly driven by the peptide phase. The low- $q$ range is characterized by a scaling law with $\sim q^{-2.1}$, consistent with planar assemblies in solution; a diffuse peak found at $q \sim 1.3 \mathrm{~nm}^{-1}$ corroborated repeat distances of $d=4.8 \mathrm{~nm}$, associated with the juxtaposition of one duplex DNA and one cross-section $\mathrm{RFL}_{4} \mathrm{FR}$ nanosheet. A small shoulder at $q \sim 2.1 \mathrm{~nm}^{-1}$, ascribed to in-plane DNADNA spacing, was noticeable only at $100 \% \mathrm{D}_{2} \mathrm{O}$, when incoherent scattering was kept to a minimum and improved signal-to-noise ratio allowed for its observation. At $66 \% \mathrm{D}_{2} \mathrm{O}$, DNA scattering was minimized and the presence of a peak at $q \sim 1.3 \mathrm{~nm}^{-1}$ confirmed that this periodicity arose from self-assembly of the peptide phase. At $39 \% \mathrm{D}_{2} \mathrm{O}$, with peptide signal reduced, SANS profiles resembled those found in DNA rods (see SI file, Figure S1). The peak at $q \sim 1.3 \mathrm{~nm}^{-1}$ appeared diffuse and suggested that DNA fragments form a periodic array within the layered structure of the peptide phase. At $0 \% \mathrm{D}_{2} \mathrm{O}$, the low $q$ scaling behaviour was 
recovered and the correlation peak at the intermediate region disappeared due to incoherent scattering of water.

Based on the scattering data presented above, we propose models to describe spatial ordering in the complexes formed either by $\mathrm{PRW}-\mathrm{C}_{16}$ or by $\mathrm{RFL}_{4} \mathrm{FR}$ peptides. Schematic drawings of these models are shown in Figure 3, where both large-scale and local structures are depicted. Also, tentative self-assembly pathways leading to the formation of PA/DNA complexes are shown with intermediate condensation steps. The lipopeptide-based complex, shown in Figure 3A-E, is represented by irregular aggregates with surface fractal features and an inner structure containing local domains with a lamellar organization. The process likely starts with the condensation of lipopeptide micelles mediated by highly-anionic DNA strands (Figure 3A), which leads to the formation of aggregates with increased amphiphile concentration followed by fusion into short-range lamellar domains (Figure 3B). Within these domains, interdigitated bilayers appear intercalated with DNA fragments hosted in hydrophilic channels with a layer periodicity of $\sim 5.6 \mathrm{~nm}$ (Figure 3C). These local structures are composed of only a few correlated layers, and loops interconnecting neighbouring membranes were introduced into the model to represent fusion and allow folding to fit bilayers and plasmid into small lamellar domains. Interactions between these domains (Figure 3D) could lead to the appearance of long-range fractal aggregates (Figure 3E). This picture is also consistent with the fluid behaviour of amphiphile mesophases and provides microphase environments where peptides and DNA appear to be spatially separated. In the case of bolaamphiphile-based complexes, (shown in Figure 3F-I), the large-scale assembly is represented by peptide nanosheets forming a sandwich with nucleic acid strands in-between. The pathway also starts with DNA chains mediating the condensation of nanosheets into sandwiched assemblies (Figure 3F). Due to the high-crystalline order of the nanosheets however, the overall planar structure of the complex is maintained (Figure 3I; discussed below). Local ordering is characterized by DNA chains condensed onto peptide surfaces, forming weakly-ordered galleries with interaxial spacing of $\sim 3 \mathrm{~nm}$ (Figure $3 \mathrm{H}$ ). 


\section{Structural analysis of peptide complexation with plasmid DNA}

The second part of our study focused on complexes prepared using peptide amphiphiles and the plasmid vector pEGFP-N1. Samples were prepared under the same conditions used in the case of small DNA fragments, i.e., complexes were formulated in buffered solutions (100 $\mathrm{mM}$ Trizma, $\mathrm{pH}=7.4$ ) and with peptides and DNA mixed at a 1:1 arginine-to-phosphate ratio. Figure 4 shows SAXS data from pellets containing peptide and plasmid. It can firstly be seen that scattering from plasmid complexes was remarkably similar to profiles found in conjugates prepared with DNA fragments, indicating that the local structure did not depend on the size of the nucleic acid sequence. In fact, although the contour length of pEGFP-N1 is much greater than that of the fragments used in model complexes $\left(L_{\text {plas }} \sim 4,700 \times 0.34=1,600 \mathrm{~nm} ; L_{\text {rods }} \sim 150\right.$ $\times 0.34=50 \mathrm{~nm}$ ), one observed that SAXS from plasmid solutions was quite similar to data obtained from solutions with DNA rods (see SI file, Figure S2). The core radius for plasmids was fitted at $R=1.1 \mathrm{~nm}$ and shell thickness at $\Delta R=0.47 \mathrm{~nm}$, slightly bigger than values found for sonicated DNA fragments. The length $(L)$ of the cylinders was found to be $145 \mathrm{~nm}$ (see SI file for all parameters). This arose because structural differences in this case were likely to appear at larger scales and the contribution from longer DNA chains was beyond the detection range of the technique. Therefore, in the range probed in our SAXS assays, structural features of both plasmid- and DNA fragments-based complexes were essentially the same and only slight differences were observed between formulations. In the case of PRW- $\mathrm{C}_{16} / \mathrm{pEGFP-N} 1$ conjugates (Figure 4A) the first-order Bragg peak associated with the mean separation between domains appeared at $q_{0}=1.14 \mathrm{~nm}^{-1}$, leading to a direct-space distance $(d)$ of $5.5 \mathrm{~nm}$. There was also a diffuse peak at $q \sim 2.3 \mathrm{~nm}^{-1}$ which could either represent a second order Bragg peak and/or it could have arisen from the preferred separation of DNA within the peptide nanostructure. The correlation length related to inter-domain spacing is $\xi=30.2 \mathrm{~nm}$, marginally higher than the value found for the homologous system with DNA. In the case of $\mathrm{RFL}_{4} \mathrm{FR} / \mathrm{pEGFP}-\mathrm{N} 1$ 
complexes (Figure 4B) the periodicity arising from the juxtaposition of one DNA strand plus one cross-section bolaamphiphile monolayer remained the same $(d=4.9 \mathrm{~nm})$ and the inter-axial separation between DNA strands in the plane of the nanosheets decreased slightly to $d_{D N A}=2.9$ $\mathrm{nm}$. In contrast, the correlation length associated with the repeat distance of the structure exhibited a significant increase, from $\xi=9.1 \mathrm{~nm}$ to $\xi=24.0 \mathrm{~nm}$, corresponding to about 5 correlated layers in the complexes prepared with plasmid and bolaamphiphiles. This finding could be related to the contour length of plasmid DNA, which being substantially greater than those found in DNA fragments may have contributed to improving inter-sheet interactions. The low-angle region, carrying information from large-scale structures, exhibited a shift of the scaling exponent to $\sim \mathrm{q}^{-2.7}$ which is known to be a feature of mass fractals with branched networks. ${ }^{46}$

Cryo-TEM imaging was used to provide direct-space visualization of the topology of the complexes (see Figures 4C and D). Formulations prepared using lipopeptides and plasmids (Figure 4C) were seen to be characterized by agglomerates of a few hundred of nanometres in size, some of which appeared bound together by small threads. Inspecting aggregates in more detail, one observes highly-compact assemblies with mosaic patterns looking like interpenetrating sheets with internal structures which could be tentatively ascribed to plasmidcontaining lamellae. Fourier transforms carried out over selected portions of the surface (see inset in Figure 4C) identified the presence of periodic arrays with repeat distances of $\sim 6 \mathrm{~nm}$, in good agreement with the separation observed between layers revealed by scattering experiments. Although it was not possible to identify DNA strands within the assemblies, threads escaping from the complexes had cross-sectional dimensions compatible with the diameter expected for DNA chains, implying that polynucleotides were likely to be hosted in the interstices of the layered structure. High-magnification imaging (Figure 4E) revealed small lamellar domains with alternating bright and dark layers. The separation between layers was consistent with the periodicity found in SAXS experiments and the appearance of interconnected galleries was clearly visible, in close agreement with the schematic representation shown in Figure 3C. In contrast, the complex formulated with the bolaamphiphile 
(Figure 4D) exhibited the coexistence of tape-like assemblies and fibrils forming a branched network and being consistent with large-scale features revealed by SAXS. The images do not allow for cross-sectional visualization of sandwiched arrays. However the typical thicknesses of tape structures ranging from $\sim 8 \mathrm{~nm}$ to $\sim 25 \mathrm{~nm}$ were enough to accommodate several galleries of DNA strands absorbed onto the plane of the tapes. Magnified images showing the assemblies in more detail, Figure 4F, revealed the presence of plasmid segments lying on the peptide surface. Moreover, the average diameter of threads observed across the sample was found to be $\sim 5 \mathrm{~nm}$, which is much thicker than the size expected for a duplex diameter. We propose that bolaamphiphile octamers may be condensed in the surroundings of plasmid strands. In addition, the appearance of these presumed peptide/plasmid threads bound to tape-like assemblies suggested a fusion process leading to flat tape-like assemblies.

X-ray diffraction was carried out to provide sub-nanometre details on the organization of PA/pEGFP-N1 complexes. In Figure 5, two-dimensional diffractograms resulting from these experiments exhibited characteristic patterns comprised of concentric Bragg rings. Diffraction data from single-component samples (Figures 5A-C) and plots of radially averaged intensities as a function of $2 \theta$ (Figures $5 \mathrm{~F}$ and $\mathrm{G}$ ), are also displayed for comparison. It should be noted that the method used for sample preparation led to non-oriented fibres, this being the reason for the powder-like DNA patterns obtained by us (Figure 5A), and these do not resemble the classical X-shaped behaviour found in highly-oriented fibres. ${ }^{47,}{ }^{48}$ Peak positions in the DNA diffractograms were closely indexed by an orthorhombic unit cell with lattice parameters $a=$ $3.12 \mathrm{~nm}, b=2.27 \mathrm{~nm}$ and $c=3.37 \mathrm{~nm}$, which has been widely ascribed to the $B$-form of the double helix ${ }^{49-51}$ (see inset with the simulated pattern in Figure 5A). Data from peptides showed different levels of order depending on the nature of the amphiphile used in the formulation. Diffraction from the PRW-C 16 lipopeptide (Figure 5B) was characterized by three diffuse rings, indicating periodic structures with low correlation lengths. A strong reflection at $2 \theta=2.31^{\circ}$, associated with repeats of $d=3.82 \mathrm{~nm}$, was ascribed to diameters of dehydrated self-assemblies (fibrils), whereas a weak band centred at $2 \theta=6.87^{\circ}(d=1.3 \mathrm{~nm})$ likely arose from $\beta$-sheet 
spacing between tripeptide polar heads, in agreement with FTIR data (see SI file, Figure S3). A diffuse outer ring appeared at $2 \theta=19.89^{\circ}(d=0.45 \mathrm{~nm})$, being attributable to separation between alkyl chains. ${ }^{29}$ These reflections were straightforwardly indexed to a simple orthorhombic cell with parameters $a=3.82 \mathrm{~nm}, b=1.3 \mathrm{~nm}$ and $c=0.45 \mathrm{~nm}$ (see inset). The XRD pattern from $\mathrm{RFL}_{4} \mathrm{FR}$ bolaamphiphiles showed reflections that were much sharper, indicating a higher crystalline order in these samples. The array was organized into a cross- $\beta$ structure indexed to an orthorhombic unit cell with lattice parameters $a=3.29 \mathrm{~nm}, b=1.14 \mathrm{~nm}$ and $c=0.96 \mathrm{~nm}$, as previously published. ${ }^{16}$

In contrast to SAXS data, which could not be properly described by combinations of contributions from the individual components, the XRD reflections from complexes were more straightforward and were interpreted by superposing the repeat distances appearing in the DNA or peptide diffractograms. In Figure 5D, the wide-angle region of plasmid/PRW- $\mathrm{C}_{16}$ patterns was dominated by the diffuse ring ascribed to separation between alkyl chains in the lipopeptide structure. On the other hand, a feature of the low-angle region was Bragg peaks arising from separations between phosphate groups in the DNA strands. ${ }^{49}$ Conversely, in the case of complexes prepared with the bolaamphiphile, diffraction peaks (Figure 5E) from DNA packing were more pronounced in the wide-angle region, whereas those related to peptide organization appeared either at small or at wide angles.

These findings likely indicate that complexation does not affect the structural integrity of the pEGFP-N1 cargo which is a key requisite for any such genetic material retaining its functional capability. The absence of crystalline features in the diffraction patterns of the mixtures of peptides and polynucleotides is suggestive of weaker interactions between these species. The molecular organization of such PA/NA conjugates is a key issue for delivery to the cellular nucleus where DNA dissociation from such complexes is critical for subsequent gene expression. Another important issue in intracellular uptake is the endosomal escape of the vehicle after delivery to the cytoplasm of the cell - i.e., after releasing its cargo, the vehicle should be metabolized by cellular machinery without further interference or toxicity to the cell. ${ }^{20}$ Here, the higher fluidity observed in conjugates formed with the lipopeptide is a potential 
advantage because such weakly bound structures are presumably easier to unpack either for delivery of the load or for endosomal escape of the transfected DNA.

\section{Peptide-plasmid complexes as tools for in vitro transfection of cells in culture}

The potential of $\mathrm{PRW}-\mathrm{C}_{16}$ and $\mathrm{RFL}_{4} \mathrm{FR}$ peptides to interact with plasmid DNA was also investigated using a gel retardation assay in which the appearance of plasmid bands of reduced electrophoretic mobility is evidence of peptide-DNA interactions. Increasing dose-dependent binding of $\mathrm{RFL}_{4} \mathrm{FR}$ and PRW-C $\mathrm{C}_{16}$ to plasmid DNA was clearly in evidence (see SI file, Figure S4), observations that fully concur with those reached during the structural studies described above. PRW- $\mathrm{C}_{16}$ and $\mathrm{RFL}_{4} \mathrm{FR}$ showed greater DNA interactions when peptide quantities were higher than $\sim 300 \mathrm{ng}$ and $\sim 200 \mathrm{ng}$, respectively, after which the free DNA bands were almost completely shifted. Given that the quantity of vector DNA was fixed at $100 \mathrm{ng}$, one can estimate full complexation occurring when the number of arginine residues exceeds that of phosphate groups (arginine-to-phosphate ratios above $~ 1.5$ and $\sim 1.3$, for PRW- $\mathrm{C}_{16}$ and $\mathrm{RFL}_{4} \mathrm{FR}$ ). These findings reinforce the role of electrostatic interactions as a driving force for complexation and suggest that DNA strands act as a mediator of peptide condensation prior to fusion and leading to the formation of envelopes surrounding the nucleic acids. The ability to bind cargo through electrostatic interactions is beneficial for potential cell-penetrating peptides as there is no need for covalent linkage procedures which have the potential to alter the function or efficacy of the attached cargo. Conjugation of peptides to cargo may also be costly and laborious, an example being the generation of a conjugate of the amphipathic transporter and siRNA, a procedure that required synthesis of 5 ' thiol groups and disulphide bond formation. ${ }^{52}$

A key aspect of any reagents to be used in transfection studies is their potential for cytotoxicity. We chose to investigate this possibility using a dual cell viability assay which consisted of a mitochondrial activity assay (Alamar Blue) and a cell membrane integrity assay (CFDA-AM). It can be seen that neither peptide showed any significant negative effect on SW480 cells, a well-studied colon carcinoma-derived cell line (Figures 5A and 5B), across the 
concentration ranges used [up to $5 \mu \mathrm{g} / \mathrm{mL}$ (PRW-C16) and $4.5 \mu \mathrm{g} / \mathrm{mL}$ (RFL4FR)]. Importantly, these upper peptide concentrations were considerably in excess of those used during in vitro transfections ( $3 \mu \mathrm{g} / \mathrm{mL}$ PRW-C16 and $2.5 \mu \mathrm{g} / \mathrm{mL}$ of RFL4FR, respectively; see below) where prior complete complexation of plasmid DNA was first established (see SI file, Figure S4). Similar results were also obtained with peptide-plasmid complexes and when the 293 Human Embryonic Kidney cell line (HEK 293) was used for transfections (data not shown). The low cytotoxic effects of the free peptides and peptide complexes therefore provide an advantage in potential transfection applications in comparison to some other transfection methods such as electroporation.

We next looked for evidence of any potentiating effect of these peptides on the cellular uptake of pEGFP-N1. This has been made by assessing EGFP fluorescence from DAPI-stained nuclei. In despite accurate determinations are not achieved through fluorescent microscopy, estimations on transfection efficiency percentages could be obtained by determining the proportion of nuclei emitting the characteristic EGFP fluorescence. Prior complexation of plasmid with either peptide led to the appearance of EGFP-expressing cells following transfection of SW480 cells, in contrast to when no peptide was used (see Figure 6C). Using PRW-C16 as complexation peptide is clearly seen to give a much greater transfection efficiency (TE) than is the case with $\mathrm{RFL}_{4} \mathrm{FR}$ [average $\mathrm{TE}=2 \pm 1 \%$ and $31 \pm 5 \%$, respectively), relative to the commercial reagent Lipofectamine $2000(76 \pm 6 \%)$. Previous studies have suggested a correlation between DNA complexation ability and transfection efficiency whereby the formation of compact nanoparticle complexes is believed to facilitate membrane translocation and transfection. ${ }^{53}$ In the present study, a lower TE as reflected in fewer EGFP-expressing cells, does not necessarily indicate the inability of the $\mathrm{RFL}_{4} \mathrm{FR} / \mathrm{DNA}$ complex to penetrate the plasma membrane. It is possible that strong electrostatic interactions between $\mathrm{RFL}_{4} \mathrm{FR}$ and $\mathrm{DNA}$ may prevent sufficient complex disassembly inside the cell therefore either hindering the delivery of DNA cargo to the nucleus or preventing expression of the reporter gene. It is also possible that the complexes may become entrapped in an endosome if internalised through endocytic 
pathways, posing as an obstacle to the usefulness of many CPPs. ${ }^{54}$ The transfection capacity of PRW- $\mathrm{C}_{16}$ may be due to its combination of $\mathrm{R}$ and $\mathrm{W}$ residues and an ability to form micelles through lipophilicity. Arginine has been shown to provide electrostatic interactions and hydrogen bonding with anionic groups on the cell surface thus promoting uptake. Studies have suggested that the resulting peptide charge influenced by $\mathrm{R}$ residues can facilitate HSPG (Heparan sulphate proteoglycan) binding and also mediate entry through endocytic pathways. ${ }^{55}$ Interactions from a single $\mathrm{R}$ residue may not be sufficient to promote cellular uptake alone, however in combination with other residues, may enhance uptake. Elsewhere, tryptophan has been linked to DNA intercalation ${ }^{56}$ and membrane destabilisation. ${ }^{20}$ Lipophilic groups, such as the hexadecyl chain, have also been shown to play a significant role in cellular uptake. Prata et al. demonstrated the influence of the lipophilicity of a similar tripeptide on transfection ability, with the sequence KWK (K: lysine; W: tryptophan) indicating a lack of cellular uptake in the absence of a $\mathrm{C}_{14}$ chain. ${ }^{56}$ In the present study, the successful delivery of functional plasmid to the nucleus suggested that the interdigitated assembly formed was able to maintain stability and prevent early inappropriate disassembly. We also noted that transfection efficiencies with PRW$\mathrm{C}_{16} / \mathrm{pEGFP}-\mathrm{N} 1$ complexes were comparable in the presence and absence of serum (data not shown). This suggests that the scaffolds protect the DNA load from potential nucleases in serum and are themselves resistant to proteases and other serum constituents that may destabilise or degrade the PA/DNA complexes. This provides a significant advantage as a transfection agent as most non-viral methods show reduced transduction efficiencies in the presence of serum. In addition to nucleic acids, the structure of the PRW- $\mathrm{C}_{16}$ assemblies formed might also support the delivery of hydrophobic molecules through entrapment within the hydrophobic centre of the bilayers during their formation. 


\section{Conclusions}

We presented a comprehensive description of the self-assembly of complexes formed between DNA and arginine-containing peptide amphiphiles. For the first time, self-assembly of two major types of PAs, a lipopeptide and a bolaamphiphilic peptide, was compared under the very same conditions and both were found to easily form complexes with nucleic acids. The combination of high-resolution SAXS and contrast-variation SANS provided unprecedented insights into the structure and enabled us to accurately determine spatial ordering in both complexes.

On a scale of a few hundred nanometres, complexes based on the lipopeptide PRW-C 16 self-assembled into clustered arrays with large-scale structure exhibiting clear features of surface fractal aggregates and DNA strands remaining hosted in the interstice of the peptide phase. Interdigitated peptide bilayers, likely intercalating DNA galleries, appeared separated by repeat distances of $d \sim 5.5 \mathrm{~nm}$, indicating strong condensation of DNA which could enable penetration across eukaryotic membranes. In the case of complexes intended for gene delivery, organization into condensed nanoclusters is a potentially attractive characteristic because clustering in biomolecular arrangements usually implies weak long-range attractive interactions. ${ }^{57}$ In fact, unlike bolaamphiphile conjugates whose diffraction patterns exhibit sharp Bragg peaks arising from well-ordered structures, wide-angle XRD from lipopeptide complexes appeared to be smoother and dominated by diffuse reflections (see Figure 5F). This behaviour indicates an absence of long-range order at sub-nanometre level and is also evidence of weak non-covalent forces at play for stabilizing assemblies. ${ }^{58}$ During load release, these weakly bound structures may represent an advantage that makes for easier disassembly followed by delivery of DNA into nucleus. This is supported by transfection efficiencies estimated through fluorescence microscopy assays, which indicated that the lipopeptide-based conjugate investigated here is much more efficient for enhancing uptake of DNA in comparison to the bolaamphiphile complex. 
In bolaamphiphile-based complexes, stronger forces are presumably involved in longrange ordering and make unpacking energetically costly. We therefore propose that the crystalline nature of bolaamphiphile nanosheets hinders disassembly steps required for load release and that this is the basis for the poorer delivery capabilities observed in these complexes. In addition, these structures are stiffer and bending peptide nanosheets for wrapping nucleotide strands is a process that requires very high energy expenditure. In this case, DNA helices are probably not completely "protected" within a peptide envelope formed by bolaamphiphile sheets and could be damaged in the extracellular medium. This hypothesis is supported by cryoTEM images (see Figures 4D and 4F) that show nucleotide strands partially exposed in bolaamphiphile complexes.

Importantly, cell viability assays showed that both peptides and peptide complexes were of limited toxicity to two well-studied cell lines. Furthermore, and consistent with the structural features identified above, our preliminary transfection assays showed that PRW- $\mathrm{C}_{16}$ in particular had potential in terms of its ability to assist with gene delivery to cells in culture. Further studies will involve optimising the transfection protocol coupled with the use of an expanded range of transformed and cultured primary cells, analysing the mechanisms of cellular uptake and complex disassembly post-transfection, and investigating the capacity of PRW- $\mathrm{C}_{16}$ to deliver cargo including siRNA and molecules other than nucleic acids. In the future, we plan to investigate peptide-DNA interactions/transfection efficiencies involving alternative nucleic acid cargos such as oligonucleotides and small RNA molecules. Also, the role of different sidechains in both spatial organization and delivery capabilities will be studied by designing new peptide scaffolds in which systematic amino acid substitutions have been introduced into the primary sequences investigated in this work.

\section{Supporting Information}

SAXS modelling, fitting parameters, scattering curves, FTIR data and gel retardation assays. 


\section{Author information}

Corresponding author:

*E-mail: ersilva@ fis.ufal.br; Tel.: +55 82 3214-1423

\section{Acknowledgements}

The National Institute of Science and Technology in Bioanalytics (INCT-Bio, CNPq ${ }^{\circ}$ 573672/2008-3, FAPESP $n^{\circ}$ 08/57805-2) is acknowledged. E.R.S. is grateful to FAPESP for grants (2013/12674-6 and 2014/03514-8). Research Brazil Ireland (RBI) and the Science Without Borders (SWB) programme are kindly acknowledged for bridging the teams at UFABC and DCU. W.A.A. is funded by CNPq and FAPESP under grants 400239/2014-0 and 15/24018-1. I.W.H. is recipient of a Royal Society-Wolfson Research Merit Award and this work was supported by EPSRC Platform Grant "Nanostructured Polymeric Materials for Healthcare" (EP/L020599/1). Dr. Laurence Navailles and Annie Février (CRPP, Bordeaux) are acknowledged for providing sonicated DNA fragments. Drs. Javier Perez (SOLEIL-SWING) and Ana Labrador (MaxLab-I911-4) are acknowledged for assistance during synchrotron experiments (proposals SOLEIL: 20140919 and MaxLab: 20140431). Drs. Stephen King (ISISLOQ) and Andre Heinemann (MLZ-SANS1) are kindly acknowledged for technical assistance on neutron beamlines (proposals ISIS: RB1510029 and MLZ: 9177). E.R.S. thanks Dr. Ashkan Dehsorki and Steven Kirkham for help and discussions during data collection at MaxLab and MLZ. Bruna M. Soares is kindly acknowledged for drawing the chemical structures shown in Figure 1.

\section{References}

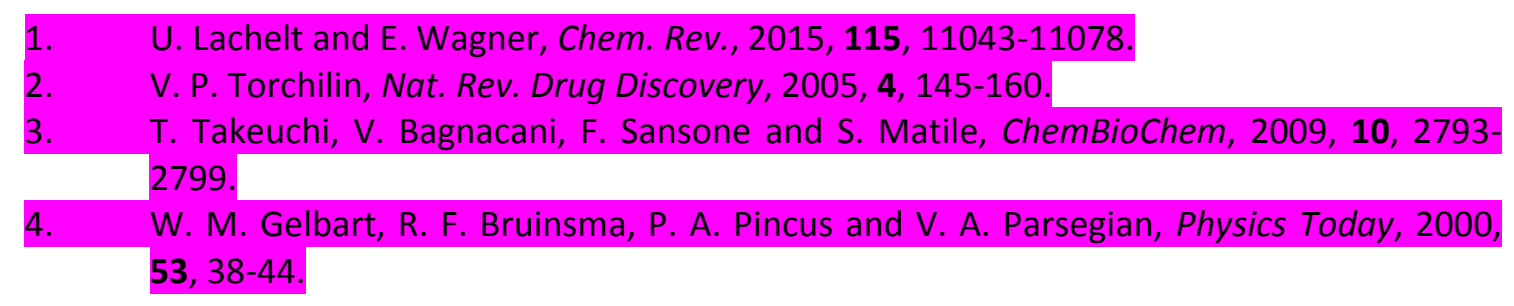


5. C. R. Safinya, K. K. Ewert, R. N. Majzoub and C. Leal, New J. Chem., 2014, 38, 5164 5172 .

6. S. May, D. Harries and A. Ben-Shaul, Biophys. J., 2000, 78, 1681-1697.

7. J. O. Radler, I. Koltover, T. Salditt and C. R. Safinya, Science, 1997, 275, 810-814.

8. C. R. Safinya, Curr. Opin. Struc. Biol., 2001, 11, 440-448.

9. P.W. Yang, T.L. Lin, T.Y. Lin, C.H. Yang, Y. Hu and U. S. Jeng, Soft Matter, 2013, 9, $11542-11548$.

10. I. Koltover, T. Salditt, J. O. Radler and C. R. Safinya, Science, 1998, 281, 78-81.

11. H. Kim and C. Leal, ACS Nano, 2015, 9, 10214-10226.

12. A. Zidovska, H. M. Evans, K. K. Ewert, J. Quispe, B. Carragher, C. S. Potter and C. R. Safinya, J. Phys. Chem. B, 2009, 113, 3694-3703.

13. A. Dehsorkhi, V. Castelletto and I. W. Hamley, J. Pept. Sci., 2014, 20, 453-467.

14. H. Cui, M. J. Webber and S. I. Stupp, Biopolymers, 2010, 94, 1-18.

15. R. F. Silva, D. R. Araújo, E. R. Silva, R. A. Ando and W. A. Alves, Langmuir, 2013, 29, 10205-10212.

16. E. R. da Silva, M. N. M. Walter, M. Reza, V. Castelletto, J. Ruokolainen, C. J. Connon, W. A. Alves and I. W. Hamley, Biomacromolecules, 2015, 16, 3180-3190.

17. I. W. Hamley, Chem. Commun., 2015, 51, 8574-8583.

18. C. C. Decandio, E. R. Silva, I. W. Hamley, V. Castelletto, M. S. Liberato, V. X. Oliveira, C. L. P. Oliveira and W. A. Alves, Langmuir, 2015, 31, 4513-4523.

19. M. S. Liberato, S. Kogikoski, E. R. da Silva, R. H. Silva, V. X. Oliveira, L. P. Scott, R. A. Ando, W. A. Alves and M. D. Coutinho-Neto, J. Phys. Chem. B, 2013, 117, 733-740.

20. C. Bechara and S. Sagan, Febs Lett., 2013, 587, 1693-1702.

21. H. L. Åmand, H. A. Rydberg, L. H. Fornander, P. Lincoln, B. Nordén and E. K. Esbjörner, Biochim. Biophys. Acta, Biomembr., 2012, 1818, 2669-2678.

22. Y. Su, T. Doherty, A. J. Waring, P. Ruchala and M. Hong, Biochemistry, 2009, 48, 45874595.

23. D. J. Mitchell, L. Steinman, D. T. Kim, C. G. Fathman and J. B. Rothbard, J. Pept. Res., 2000, 56, 318-325.

24. N. Schmidt, A. Mishra, G. H. Lai and G. C. L. Wong, Febs Lett., 2010, 584, 1806-1813.

25. Y. X. Hu, M. T. Haynes, Y. H. Wang, F. Liu and L. Huang, ACS Nano, 2013, 7, 5376-5384.

26. S. Pujals and E. Giralt, Adv. Drug Delivery Rev., 2008, 60, 473-484.

27. E. R. da Silva, W. A. Alves, V. Castelletto, M. Reza, J. Ruokolainen, R. Hussain and I. W. Hamley, Chem. Commun., 2015, 51, 11634-11637.

28. T. Wang, J. R. Upponi and V. P. Torchilin, Int. J. Pharm., 2012, 427, 3-20.

29. E. R. da Silva, E. A. de Oliveira, A. Fevrier, F. Nallet and L. Navailles, Eur. Phys. J. E: Soft Matter. Biol. Phys., 2011, 34, 83.

30. J. Dobrindt, E. Rodrigo Teixeira da Silva, C. Alves, C. L. Oliveira, F. Nallet, E. Andreoli de Oliveira and L. Navailles, Eur. Phys. J. E: Soft Matter. Biol. Phys., 2012, 35, 3.

31. O. S. Makin, P. Sikorski and L. C. Serpell, J. Appl. Crystallogr., 2007, 40, 966-972.

32. D. A. Jacques and J. Trewhella, Protein Sci., 2010, 19, 642-657.

33. T. Zemb and P. Lindner, Neutrons, X-rays and light : scattering methods applied to soft condensed matter, Elsevier, Amsterdam ; Boston, $1^{\text {st }}$ edn., 2002.

34. S. K. Bopp and T. Lettieri, BMC Pharmacol., 2008, 8:8.

35. E. A. d. Oliveira, E. R. T. d. Silva, A. Février, G. É, F. Nallet and L. Navailles, Europhys. Lett., 2010, 91, 28001.

36. J. S. Pedersen, Adv. Colloid Int. Sci., 1997, 70, 171-210.

37. M. Feig and B. M. Pettitt, Biophys. J., 1999, 77, 1769-1781.

38. J. F. Miravet, B. Escuder, M. D. Segarra-Maset, M. Tena-Solsona, I. W. Hamley, A. Dehsorkhi and V. Castelletto, Soft Matter, 2013, 9, 3558-3564.

39. T.E. Creighton, T. H. Creighton, Proteins: Structure and Molecular Properties, W. H. Freeman, New York, 1992, $2^{\text {nd }}$ edn. 
40. G. Pabst, M. Rappolt, H. Amenitsch and P. Laggner, Phys. Rev. E: Stat., Nonlinear, Soft Matter Phys., Top., 2000, 62, 4000-4008.

41. B. Hammouda, J. Chem. Phys., 2010, 133, 084901.

42. S. Motta, P. Brocca, E. Del Favero, V. Rondelli, L. Cantù, A. Amici, D. Pozzi and G. Caracciolo, Appl. Phys. Lett., 2013, 102, 053703.

43. I. W. Hamley, A. Dehsorkhi and V. Castelletto, Langmuir, 2013, 29, 5050-5059.

44. J. Yan, N. Korolev, K. D. Eom, J. P. Tam and L. Nordenskiold, Biomacromolecules, 2012, 13, 124-131.

45. G. Subramanian, R. P. Hjelm, T. J. Deming, G. S. Smith, Y. Li and C. R. Safinya, J. Am. Chem. Soc., 2000, 122, 26-34.

46. J. Teixeira, J. Appl.Crystallogr., 1988, 21, 781-785

47. R. E. Franklin and R. G. Gosling, Nature, 1953, 171, 740-741.

48. S. Arnott, Trends Biochem. Sci., 2006, 31, 349-354.

49. R. Langridge, H. R. Wilson, C. W. Hooper, M. H. F. Wilkins and L. D. Hamilton, J. Mol. Biol., 1960, 2, 19-37.

50. R. Chandrasekaran and S. Arnott, J. Biomol. Struct. Dyn., 1996, 13, 1015-1027.

51. W. Saenger, in Principles of Nucleic Acid Structure, Springer New York, New York, 1984, $1^{\text {st }}$ edn..

52. A. Muratovska and M. R. Eccles, Febs Lett., 2004, 558, 63-68.

53. N. A. Alhakamy, P. Dhar and C. J. Berkland, Mol. Pharmaceut., 2016, 13, 1047-1057.

54. F. Wang, Y. Wang, X. Zhang, W. Zhang, S. Guo and F. Jin, J. Controlled Release, 2014, $174,126-136$.

55. B. P. Meloni, D. Milani, A. B. Edwards, R. S. Anderton, R. L. O'Hare Doig, M. Fitzgerald, T. N. Palmer and N. W. Knuckey, Pharmacol. Ther., 2015, 153, 36-54.

56. C. A. H. Prata, X.-X. Zhang, D. Luo, T. J. Mclntosh, P. Barthelemy and M. W. Grinstaff, Bioconjugate Chem., 2008, 19, 418-420.

57. Y. Liu, E. Fratini, P. Baglioni, W.-R. Chen and S.-H. Chen, Phys. Rev. Lett., 2005, 95, 118102 .

58. I. W. Hamley and V. Castelletto, Angew. Chem. Int. Ed. Engl., 2007, 46, 4442-4455. 

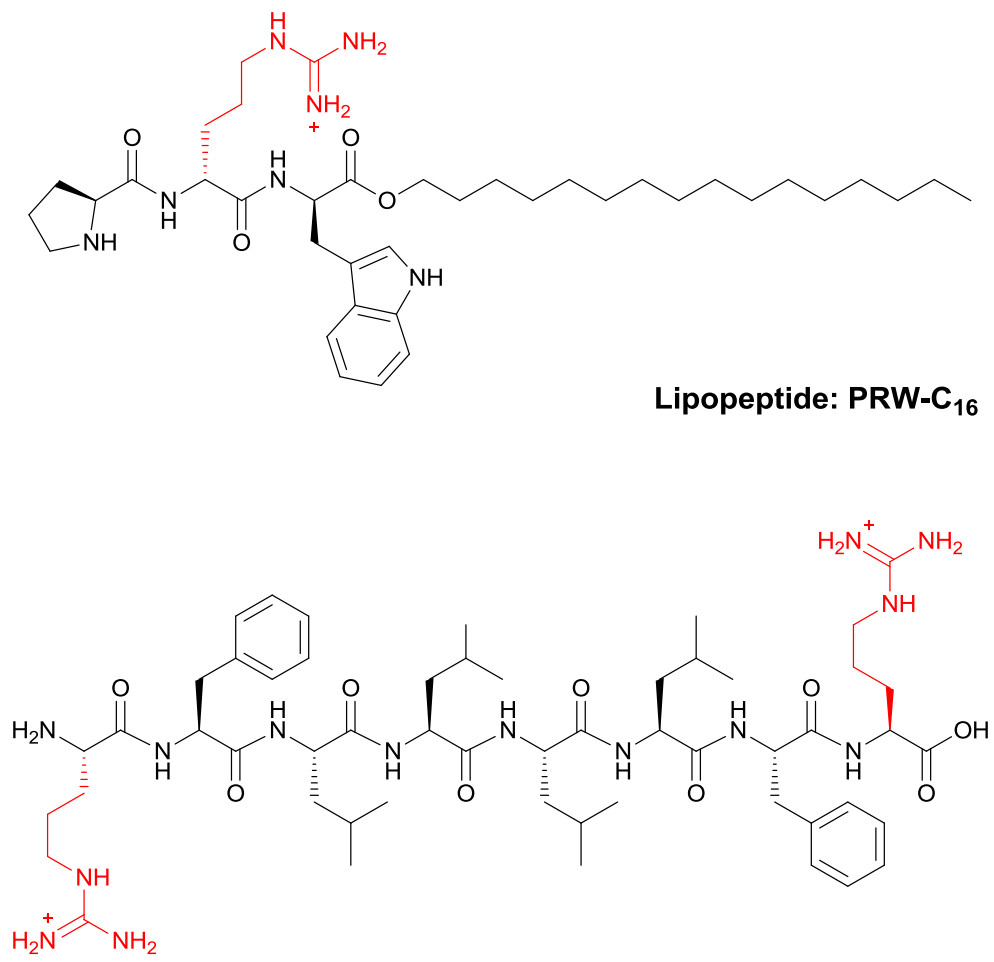

Bolaamphiphile: $\mathrm{RFL}_{4} \mathrm{FR}$

Figure 1: Chemical structures of peptide amphiphiles used in this work. Arginine side-chains appear coloured in red (colour online). 

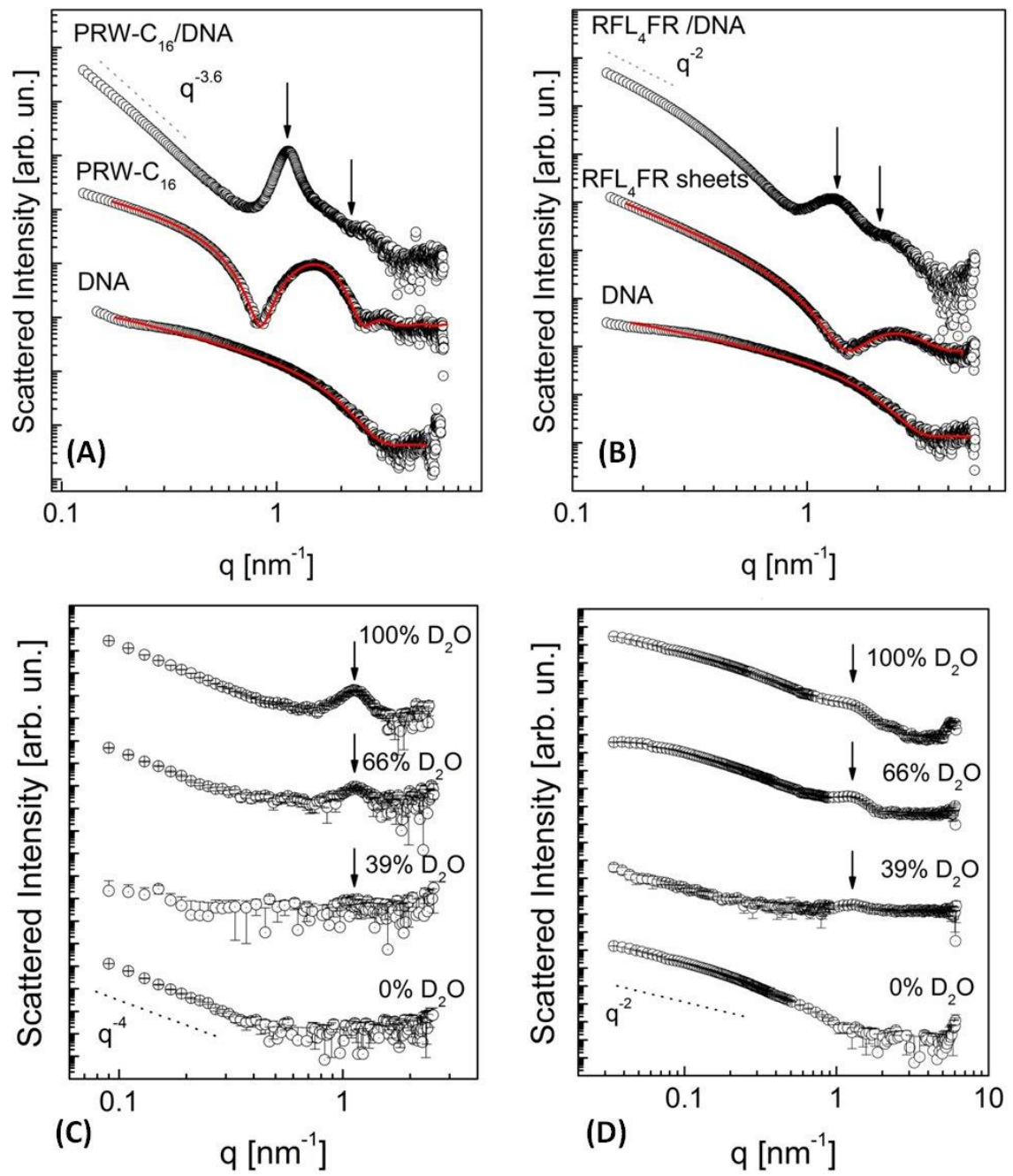

Figure 2: (A) and (B) SAXS curves from PA/DNA complexes together with data from their respective single-phase components. Conjugates were prepared with DNA fragments, at 1:1 arginine-to-phosphate ratio and final peptide concentration of $\sim 5 \mathrm{mg} / \mathrm{mL}$. Black arrows point to Bragg peaks arising from periodic structures appearing upon complexation and red solid lines (colour online) in single-phase plots correspond to model fittings described in the text. Scaling exponents of -3.6 and -2 at low-q indicate that assemblies at large-scale are characterized, respectively, by surface fractal aggregates and planar geometries. (C) and (D) SANS profiles from PA/DNA complexes. Different solvent contrasts were obtained by varying $\mathrm{D}_{2} \mathrm{O}$ content in the medium to separately match scattering length densities of peptides and nucleic acids. Black arrows highlight Bragg peaks associated to periodicities in conjugates. Differences of $q$-range are due to different instruments used for data collection (see text for details). 

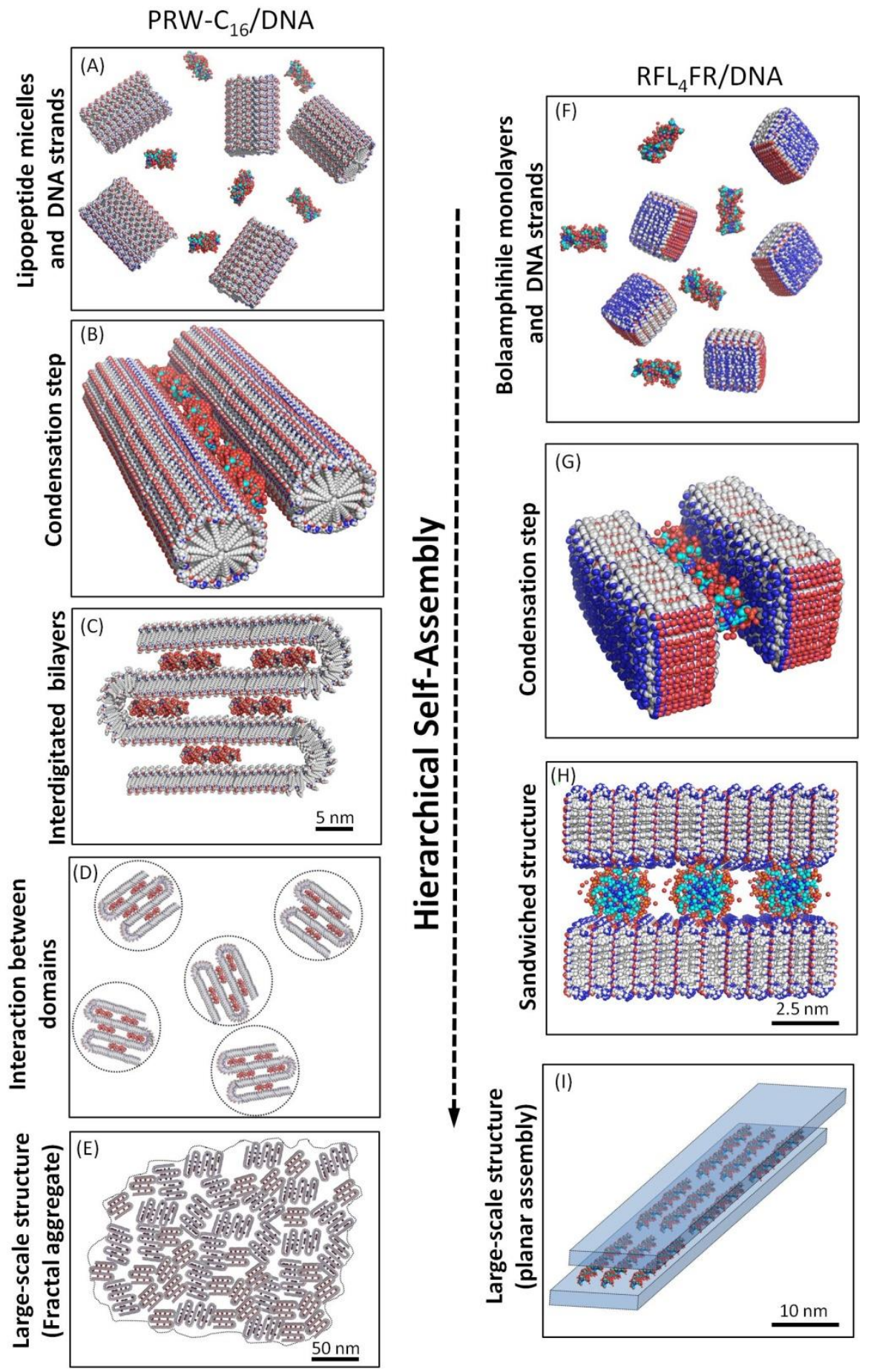

Figure 3: (Colour online). Schematic drawings of proposed self-assembly pathways and tentative structures arising from scattering data. (A)-(E) The lipopeptide-based complex selfassembles through DNA-mediated condensation of PRW- $\mathrm{C}_{16}$ micelles into interdigitated bilayers leading to the formation of local lamellar domains. The large-scale structure is builtup from inter-domain interactions leading to fractal aggregates. (F)-(I) In bolamphiphile complexes, DNA strands mediate condensation of peptide nanosheets leading to the formation of sandwiched assemblies with overall planar geometry. 

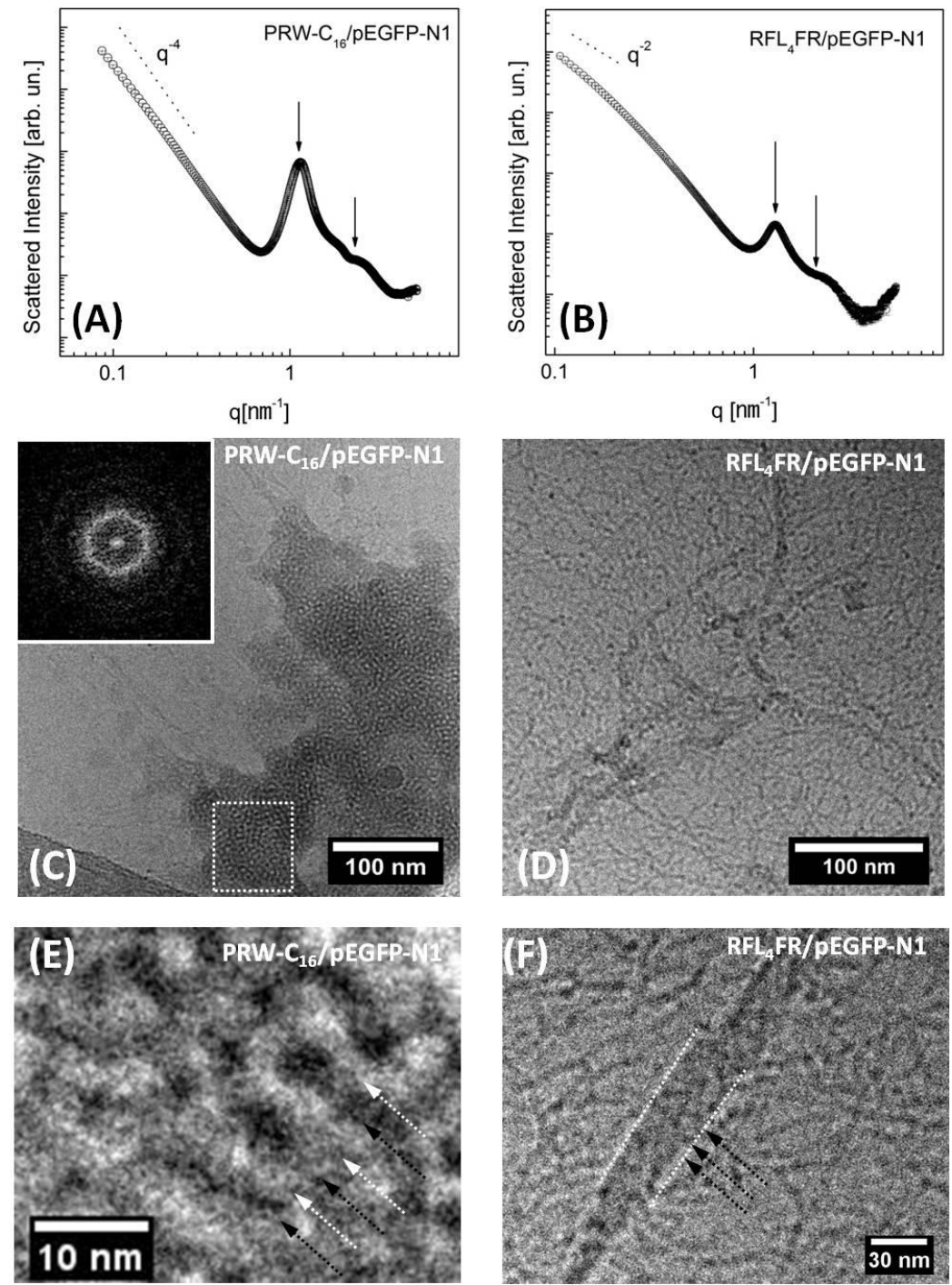

Figure 4: (A) and (B) SAXS data from complexes formed between peptide amphiphiles and the plasmid vector pEGFP-N1. The structure on the scale probed by SAXS remains essentially the same as conjugates made with DNA fragments (compare with Figure 2). (C) and (D) cryoTEM micrographs showing large-scale features of DNA complexes with PRW-C 16 and $\mathrm{RFL}_{4} \mathrm{FR}$. On the micrograph from the PRW-C $\mathrm{C}_{16} / \mathrm{pEGFP}-\mathrm{N} 1$ (C) the inset shows a Fourier transform from the region marked by a white dotted square. (E) and (F) Magnified images revealing detailed structure. For the PRW- $\mathrm{C}_{16}$ complex one observes a short lamellar domain alternating peptide (white arrows) and DNA regions (black arrows). In the bolaamphiphile complex, one sees a peptide tape-like structure (delimited by white lines) with plasmid segments absorbed onto the surface (black arrows). 

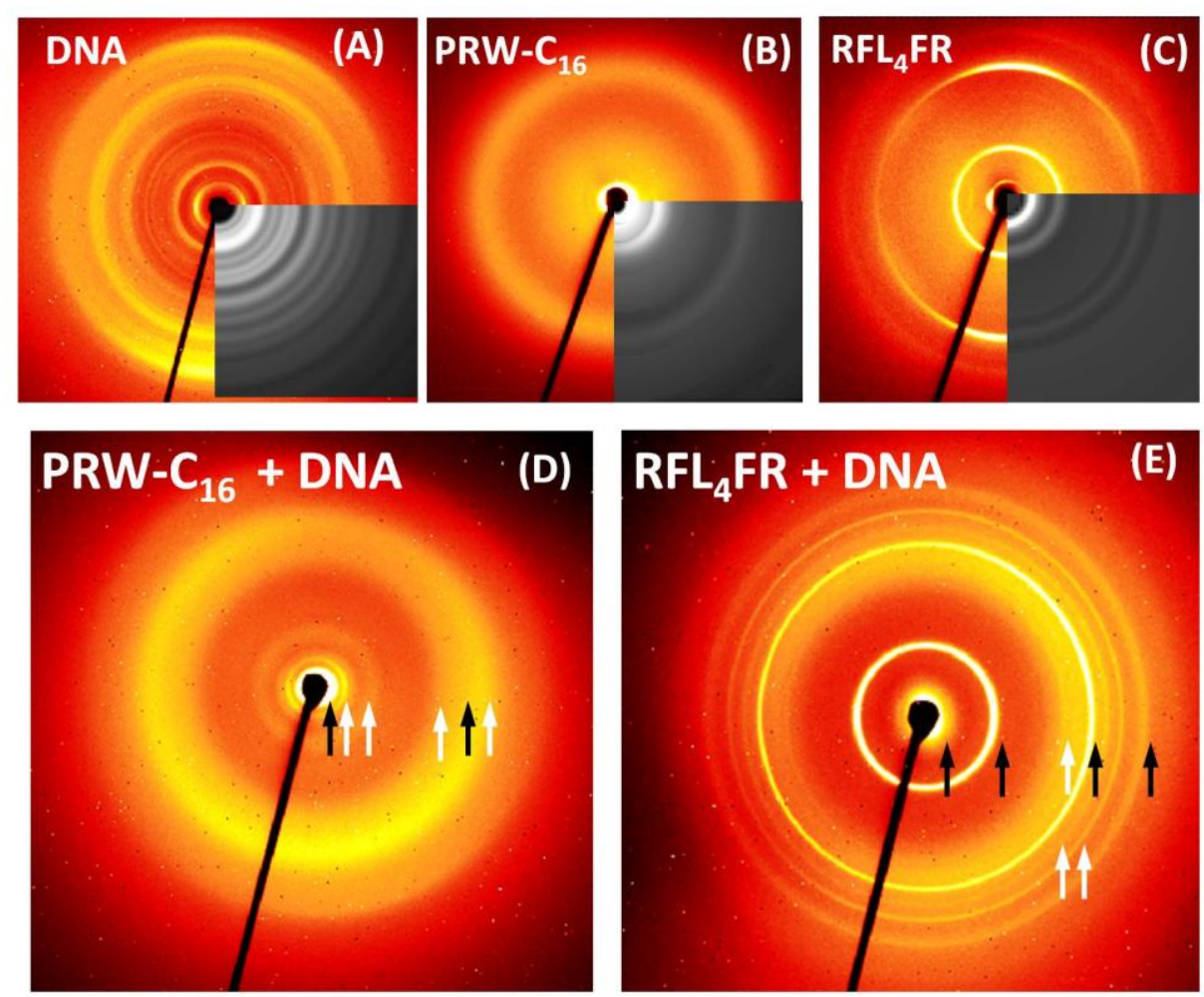

(E)
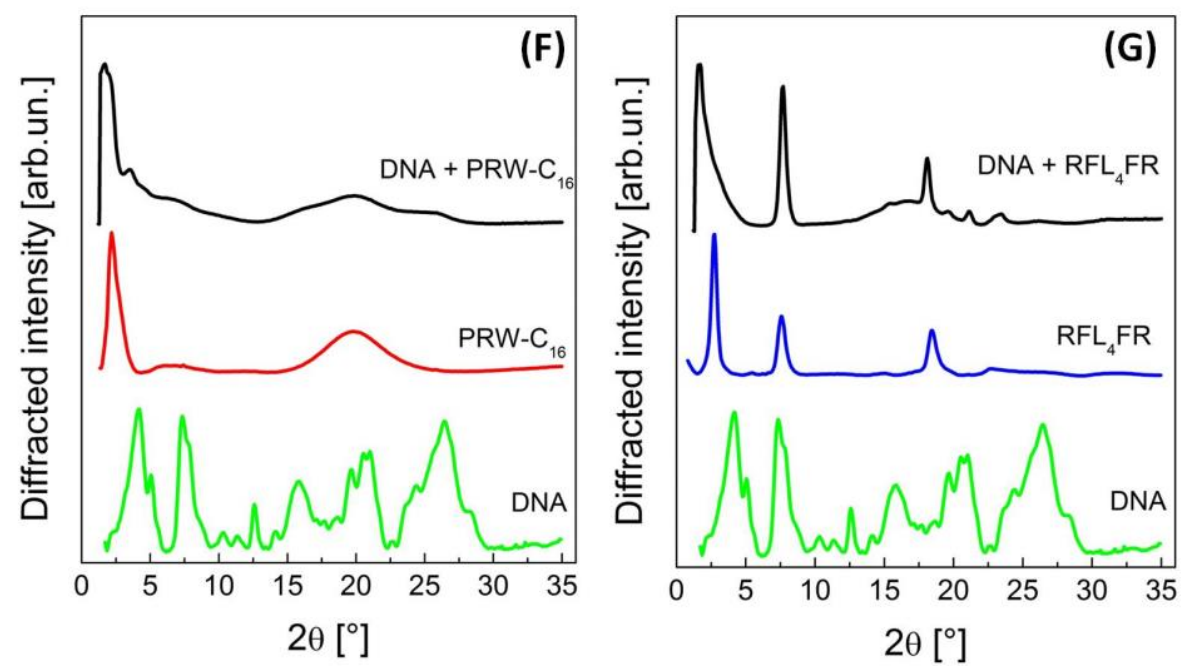

Figure 5: (Colour online). Fibre diffraction patterns from DNA, peptides and complexes. Insets show theoretical patterns simulated according to orthorhombic unit cells (see text for lattice parameters). Diffraction patterns from complexes can be described by the superposition of the individual components. 


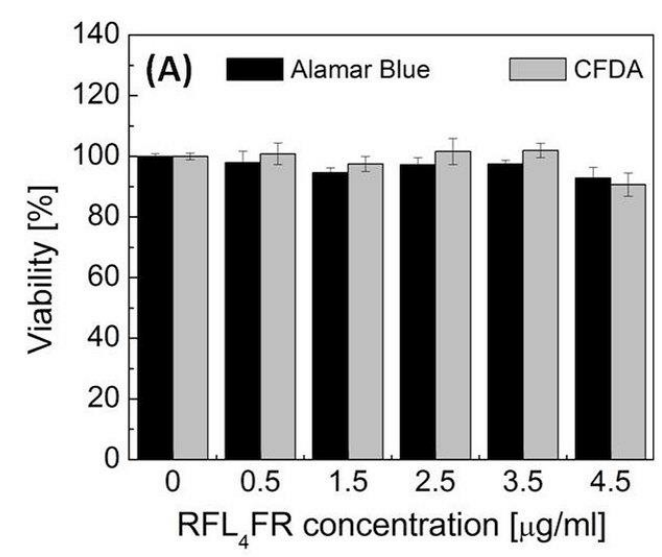

(C) DAPI

EGFP
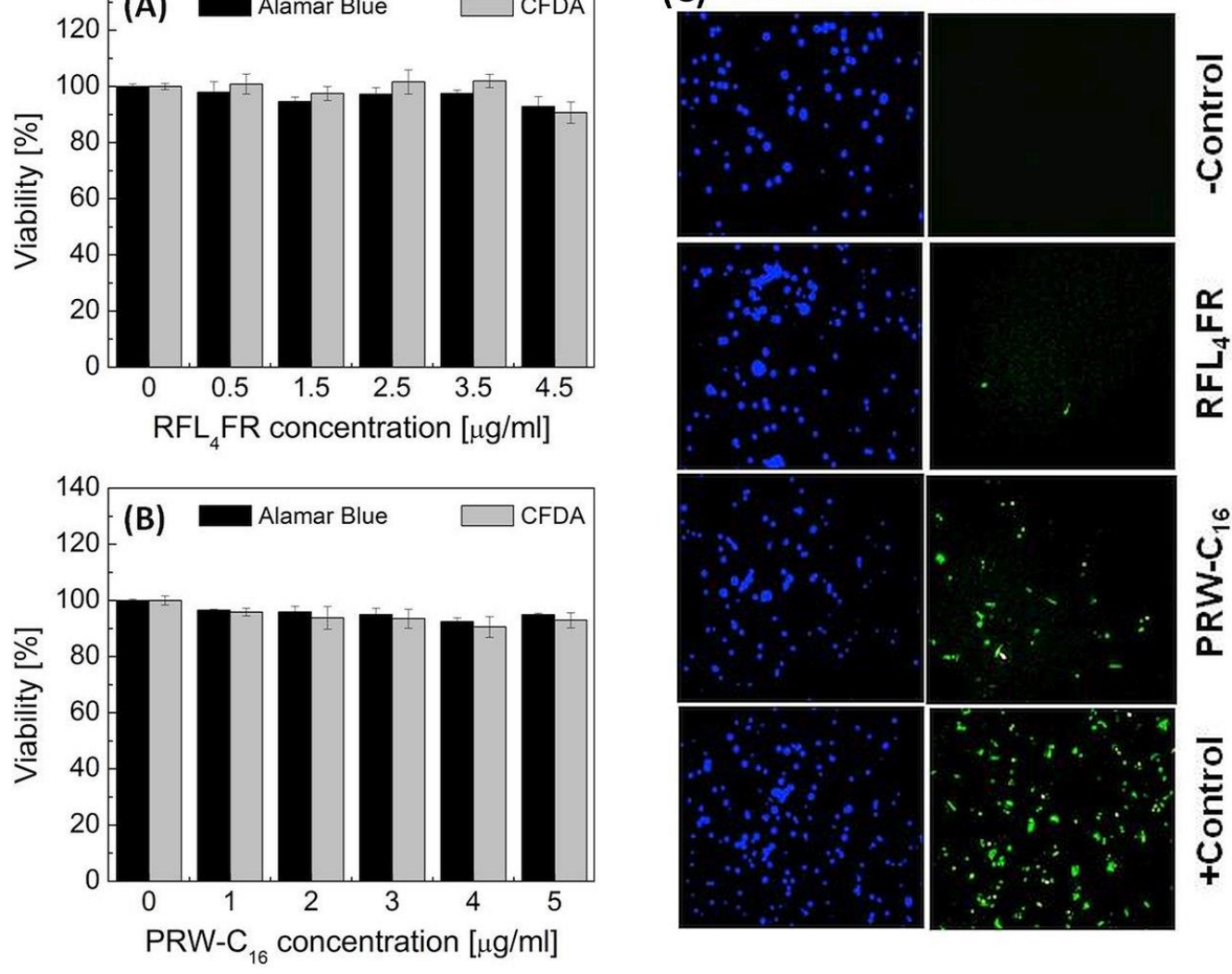

Figure 6: (Colour online). (A) and (B) $\mathrm{RFL}_{4} \mathrm{FR}$ and $\mathrm{PRW}-\mathrm{C}_{16}$ demonstrate minimal cytotoxicity against SW480 cells. SW480 colon carcinoma cells were incubated with peptides and assessed for viability $48 \mathrm{~h}$ later using the dual Alamar blue/CFDA-AM assay. The names and working concentrations of each peptide used (in $\mu \mathrm{g} / \mathrm{mL}$ ) is given underneath each bar chart. Average values of triplicates were calculated following background correction and cited as "viability (\%)" following reference to vehicle-only treated controls. All data is presented as means \pm standard deviations $( \pm \mathrm{SD})$. (C) Prior complexation of pEGFP-N1 with PRW-C 16 and $\mathrm{RFL}_{4} \mathrm{FR}$ leads to enhanced uptake of the plasmid by SW480 cells. The figure shows representative fluorescent microscopic images of SW480 colon carcinoma cells following transfection with pEGFP-N1. Panels on the left-hand side show DAPI-stained cells; the corresponding panels on the right hand side show representative results obtained with pEGFPN1 alone (-Control), pEGFP-N1/peptide complexes (peptide names are on the right hand side, and pEGFP-N1/Lipofectamine complexes (+Control). Transfected cells appear green following transfection and expression of EGFP. 


\section{TOC ENTRY}

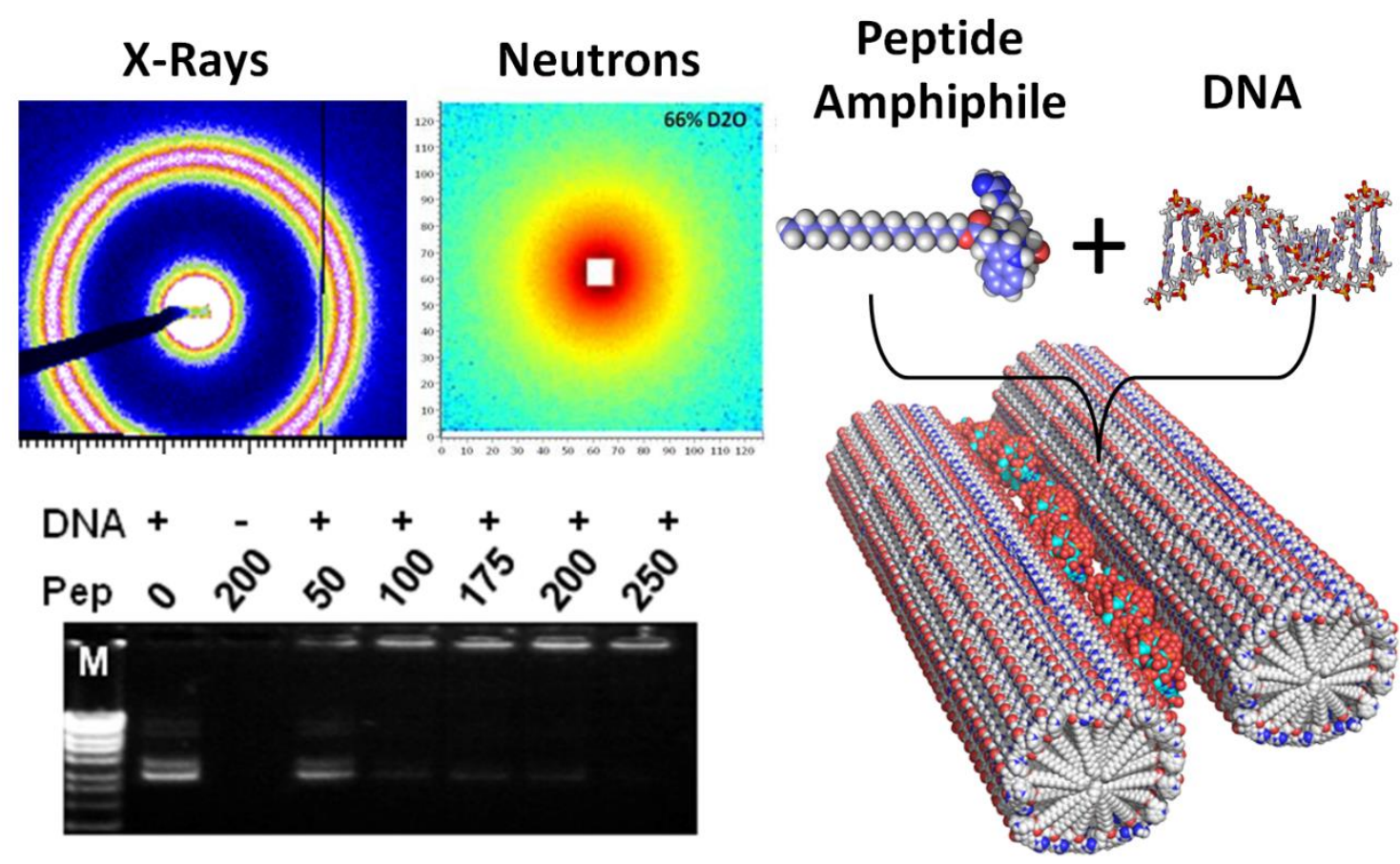

